\title{
Proposals emerging technologies for the care of water in homes
}

\author{
Alexis Delgado ${ }^{1}$, Enrique Lee Huamaní ${ }^{2}$, Alexandra Ramos-Bernaola ${ }^{3}$, MarianneAldude-Tipula ${ }^{4}$ \\ ${ }^{1}$ Mining Engineering Section, Pontificia Universidad Católica del Perú, Lima-Perú, kdelgadov@ pucp.edu \\ ${ }^{2}$ Image Processing Research Laboratory, Universidad de Ciencias y Humanidades, Lima-Perú, ehuamaniu@uch.edu.pe \\ ${ }^{3}$ Systems Engineer Student, Universidad de Ciencias y Humanidades Lima-Perú, aleramosb@uch.pe \\ ${ }^{4}$ Systems Engineer Student, Universidad de Ciencias y Humanidades, Lima-Perú, maraldudet@ uch.pe
}

\begin{abstract}
The topic that will be developed throughout this document is very important since it can affect us now or in the future, such as water scarcity, whose main causes are water pollution, such as eutrophication, which is the accumulation of toxic waste in our lakes, rivers and seas, as well as in the mining tailings made 50 years ago, which has brought many consequences for our health, making this resource less accessible to man, such as the over exploitation of this resource, Therefore, in this work we will use the RAD methodology, in which, when carrying out this research, it is proposed to develop the application called "AWAPP", in which the use of water for the different activities that involve it is delimited, therefore, achieving a reduction of the scarcity of this resource by $20 \%$ and ensuring that better care is taken with the excessive use of water, which is expected not to be exhausted over the years, since it would cause an environmental impact with respect to the conscious use of water.
\end{abstract}

Keywords:Water use, Water pollution, RAD methodology, mobile application.

\section{INTRODUCTION}

Currently, the most common problem worldwide regarding water scarcity and quality, such as water pollution, according to the United Nations Organization for Education, Science and Culture "UNESCO" [1] is the eutrophication, that is, the accumulation of organic waste in our seas. Which deteriorates the beneficial uses of water, since more than $80 \%$ of the wastewater in the Netherlands is discharged without treatment, achieving the contamination of rivers, rivers and coastal areas. Of the most notorious cases in the regions of our Peru we can speak of strong contamination by mining works, such as those caused in Arequipa. Since large companies are the cause of immeasurable damage and what has caused irreversible consequences to our nature. The pollution caused in the Rímac river is also due to mining activity that causes dangerous consequences for the population's health, taking into account that in July 2019 there was a concentration of 2.21 iron $\mathrm{mg} / 1$ (milligram per liter) which represented an increase of $51.4 \%$ in relation to the previous month, having only $1.46 \mathrm{mg} / 1$ [2].

To demonstrate more clearly the information given, on water care, we have the data provided by SEDAPAL, thus having one of the districts that consume much more water daily is San Isidro, consuming 447.5 liters of water per day and having LuriganchoChosica as one of the districts that only consume 15.2 liters of water per day [3]. Having these results, it was projected that in 2025 more than 3,000 million people would live in countries in which they suffer water stress and on the other hand 14 countries that only suffered from water stress would suffer from a lack of it, thus having in countries of the Middle East and North Africa, they would suffer a considerable decrease of more than $25 \%$ availability of this resource, in addition to $90 \%$ of the population that will live without access to water. For this reason, it is planned that more than 48 countries will face this deficit, with India, Nigeria, Kenya and Peru likely to be affected countries within the next 25 years. [4].

For this reason, the important point for developing "AWAPP" and our research is to achieve water care, since this resource is very limited and there is only a fixed quantity on our planet, thus having $97 \%$ of the water found in our oceans, but most of this, is trapped in the ice caps found in Antarctica, leaving only $1 \%$ for human consumption, coming to find them in our freshwater lakes and rivers [4], having as results given by the Service of Drinking Water and Sewerage of Lima "SEDAPAL", that a person can consume a maximum of 163 liters of water a day [5], but what is recommended according to The World Health Organization "WHO" is that a person should consume 100 liters a day, having as a total quantity that a family made up of only four people consume a maximum of $20 \mathrm{~m} 3$ per month [6].

Thus, in order to develop our research topic, there are several methodologies, which can help us to carry it out correctly, such as agile methodologies [7], including the Scrum methodology [8], which allows us to carry out a more focused approach. empirical, since it supports flexibility, as well as 
capacity and productivity showing a much more stable environment, opting for an implementation in which developers carry out the development of certain particular codes, we also have another methodology called XP or Extreme Programming [9], where the programmers of the different applications are rapidly developing the execution of a software, so that their entire environment adapts much better to the different business desires that are constantly changing, since this methodology consists of small iterations, which present little publication, but make quick reactions to any problem and for u Lastly, we have another methodology called Cristal [10], which allows prioritizing the different tasks that will be carried out within the chosen project, so that it can be organized and can be elaborated, being implemented to carry out extensive efforts and make them easier to develop. . But to achieve the implementation of this project, RAD methodology will be used [11], since this methodology allows us to instantly carry out any system that is required to be implemented, since it allows us to present a product much faster, and thus be able to implement improvements in short times [12].

As a case study, the different phases that make up the RAD methodology are presented, so in this section the results obtained will be implemented by showing the app developed to small groups of the population, from which different suggestions will be obtained, which will be analyzed and implemented both in the development of the app and in the control system, presenting the different parts of the update with their respective description in detail, thus having, that for the development of AWAPP, different tools will be used, such as for their prototyping, which The basic tool Balsamiq Mockups and Android Studio will help, having the Java code as the programming language, for the design of the app graphic elements such as Adobe Illustrator and Adobe Photoshop will be used and for the database we will use the SQL-Server as You can see in the architecture of Fig. 2 where the different tools already mentioned are found, as well as pre The architecture of the control system as can be seen in Fig. 3, where we will use the infrared sensor that will detect if the position of the key is correct, we will also use the Arduino which will help for the validation of the information, another component It will be the XBEE s2 that will transmit the information to the mobile phone so that the distribution of water in each home can be controlled and thus take care of this important resource in a favorable and prolonged way.

Thus, the objective of this research work is to care for this important resource such as water in a considerable and effective way, projecting people to a conscious use of this natural resource, being in a more sustainable way, that is to say that they adhere to their lifestyle, in order to help other people who do not have the facility to obtain this important resource, since according to the results provided by the INEI [13], only in areas of residence $94.4 \%$ of the population They access the use of this service, but we only reached $71.9 \%$ in rural areas, seeing only an increase of $0.5 \%$.
This work consists of the following structure, in section II we will be able to describe in greater detail the methodology required for the implementation and design of the system. In section III the use cases will be shown and finally in section IV the results and discussion that we want to obtain when implementing the use of our system.

\section{METHODOLOGY}

The methodology we will use is rapid application development (RAD), which consists of a highly productive development environment, in which there are small groups of developers, who use tools, which manage to generate code quickly, who take the syntax from another level, but in general is considered one of the first to achieve agility in the development process [14], since we will build an interactive development prototype that will help reduce pollution and care much more in a certain way the water.

The methodology we will use consists of 4 very important phases that we can see in Fig. 1, which allow us to carry out our project in an easier way so that its execution can be done in a much more ordered and understandable way towards the public that will make use of our application.

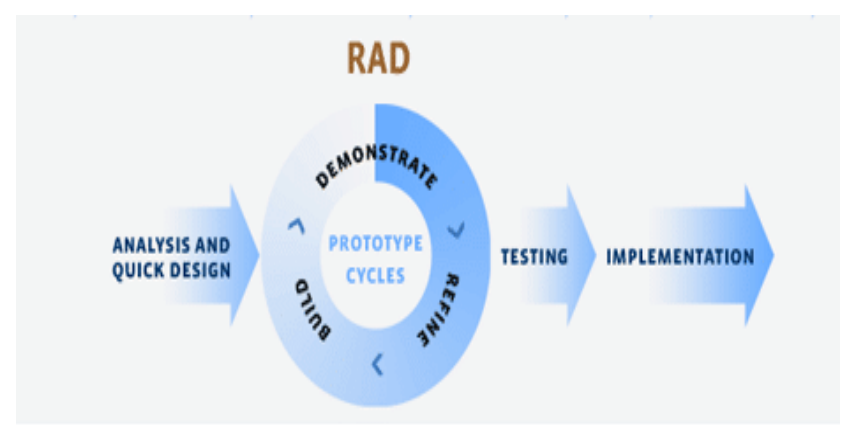

Figure 1: RAD methodology

The 4 phases to be developed are the following:

Phase 1: Requirements planning. - In this first phase we will look for reliable results in which we will obtain the origins that cause the bad use of the water, so that the necessary requirements for the suitable development of our investigation can be established.

Phase 2: Design. - In this second phase we intend to establish the structure as well as the type of software and the programming language that we will use as the necessary resources for its implementation, since it will have different modules in which different parts of our application will be presented. This phase will be considered as a prototype, since the respective changes will be made taking into account the improvements that will be proposed to the development of our project. 
Phase 3: Construction. - In this third phase we will begin the basic development of our application where most of the coding, testing and actual integration of the application will be carried out so that the appropriate modifications can be made to meet the needs of our research work.

Phase 4: Implementation. - In this fourth phase we will try to present the first sample of the application to the users, since having the application we will provide a small tutorial taking simple steps with the intention of adapting them to the use of this new app.

\section{CASE STUDY}

This section of the research will explain in a more detailed way the phases that make up this methodology, which will be used for the correct development of our application:

\section{A. Phase I}

In this phase we will show the results of the origins that manage to cause the shortage of our waters, these results that we will show are provided by different investigations that were carried out on this world problem. As a worker it is necessary to record the time of entry and exit to keep track of working hours.

In these results we have two important factors that cause the shortage of water, one of them is the contamination of the Water, due to the throwing of garbage and remainders to the drainage or the rivers, due to this, it is not possible to count on the necessary operators so that they manage to clean our rivers completely, within this factor that is the contamination we found the mining tailings for 50 years, which mineralize the water or also manage to contaminate to great amounts our waters, thus harming the health of all the citizens.

The second cause is the overexploitation of this resource, such as the bad use of water used for agriculture, since large amounts of this resource are lost in the irrigation process, due to the fact that most of these irrigation systems perform their function inefficiently, losing approximately $60 \%$ of the water they manage to extract [4].

\section{B. Phase II}

In phase II, the structure of our mobile application will be explained and shown. These will have different tools such as the type of language, the basic tool and the design program in which our app is developed, as well as the elements that will be part of the household water control system, which will be described in detail:

\section{- Mobile Application: "AWAPP":}

1. Basic tool: The first tool to be used for the prototyping will be Balsamiq Mockups 3 and for the development of the application we will use Android Studio, having as a concept that:

- Balsamiq Mockups 3.- It is a tool used to quickly and easily design mockups of interfaces for different platforms, either for a website or for mobile applications. This tool gives us the free use as the paid one. [15].

- Android Studio. - It is an integrated development environment (IDE), which allows the programming and development of apps for Android, based on INTELLIJ IDEA from JetBrains, which presents improvements of the ADT plugin (Android Developer Tools) for Eclipse. This tool is programmed in Java and in several multiplatform. [16].

2. Programming language: For the development of this App the Java language will be used for the structure of the code, having as a concept that:

- Java. - It is a programming language that has a computer platform that is considered irreplaceable, since it allows the correct operation of its various existing websites, as well as for the presentation of various applications for Smartphone devices or computers. [17].

3. Design programs: For the implementation of the graphic elements that will be used in our App, it will be used, having as a concept that:

- Adobe Illustrator. - It is a program that allows the vectoral graphic and the due design of graphic elements that are compatible for any type of support and mobile device. It is developed by Adobe Systems Incorporated. [18].

- Photoshop. - This is a computer program that allows image editing, and is also developed by Adobe Systems Incorporated, with Apple and Windows as operating systems. [19].

4. Database tools: To achieve the storage of the data that will be used in the development of our App, we will make use of SQL - Server, having as a concept that:

- SQL Server. - It is a relational database management system (RDBMS) from Microsoft, it is designed for the business environment. This program runs on 
T-SQL(Transact-SQL), which has a set of programming extensions from Sybase and Microsoft and also different features to standard SQL, including transaction control, exception and error handling, file processing and declared variables. [20].

Having thus the architecture of our mobile application as seen in Fig. 2 for its proper implementation.

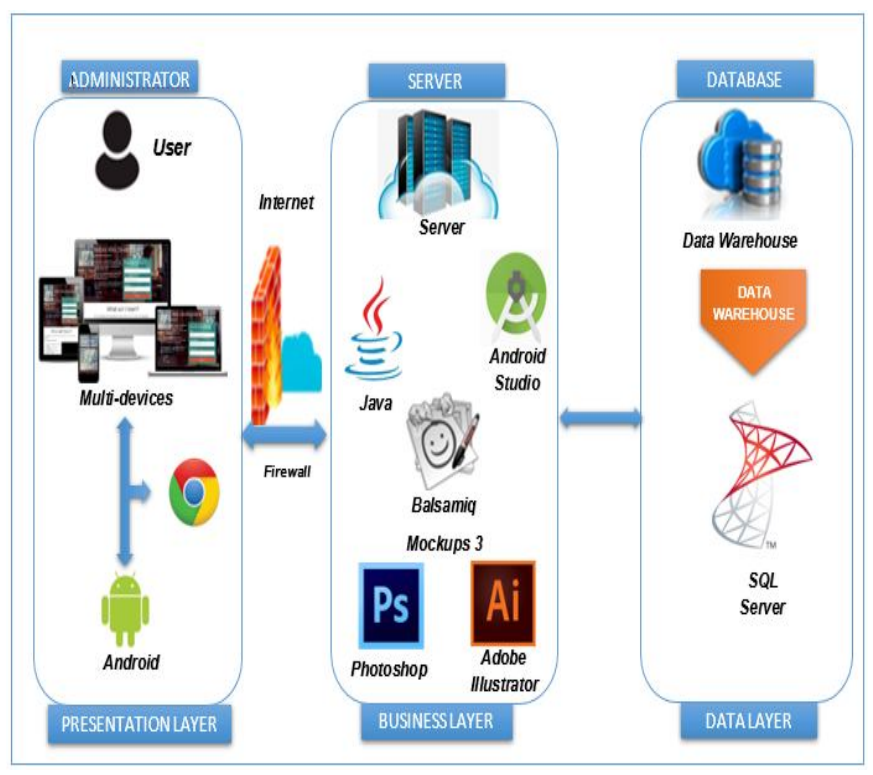

Figure 2: User/Server architecture of the mobile application to be implemented.

\section{- Home Water Control System:}

1. Connection/Interaction Tools: To make the proper connection between our control system and our application "AWAPP", will be through the XBEE s2 and the cell phone. Having as a concept that:

- XBEE s2.- They are integrated solutions that provide a wireless medium for interconnection and communication between devices. These modules use the network protocol called IEEE 802.15.4, which create FAST POINT-TO-MULTIPOINT networks, or PEER-TO. PEER networks. These modules were designed for applications that require data traffic, low latency and a good predictable communication synchronization, the Xbee is a property of the Digi in the Zigbee protocol. [21].

- Mobile or Cell Phone. - It is a wireless electronic device that has access to the network through coverage that interact with the device, sending and receiving signals with it. [22].

2. Control Tools: To have a good handling of our system we will use the Infrared Sensor and the electro valve, having as concept that:

- Infrared sensor. - They are optoelectronic devices that manage to measure the infrared electromagnetic radiation of bodies in their field of vision. It is used for temperature and detects hot objects also allows night vision and pass through some opaque objects. [23].

- Solenoid valve. - They are devices that respond by means of electrical pulses, these circulate through the solenoid coil since it is possible to open and close the valve by controlling the flow through the pipe line. [24].

3. Configuration Tools: To achieve proper water control, the Arduino will be used for programming. Having as a concept that:

- Arduino. - It is a free hardware platform, being a board with a microcontroller, which has a software environment that is designed to facilitate electronic use in multidisciplinary projects. [25].

Thus, forming our architecture as seen in Fig.3 for the household water control system.

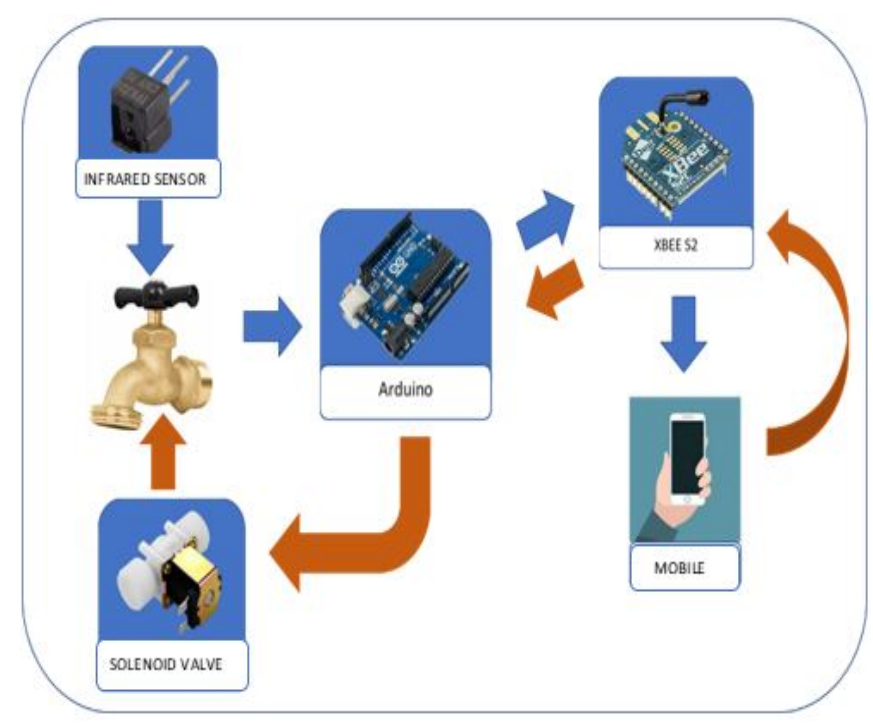

Figure 3: Water Control Architecture to be implemented. 


\section{Phase III}

In this third phase we will begin with the development and explanation of the prototype of our application called AWAPP, as mentioned above this application will be prototyped with the help of Balsamiq Mockups 3 and then developed with Android Studio, as well as what our water control system to be implemented in homes consists of.

\section{- Mobile Application: "AWAPP":}

Our application will start with a splash, which will show the AWAPP logo and then give the respective welcome and registration or access options as shown in Fig.4.
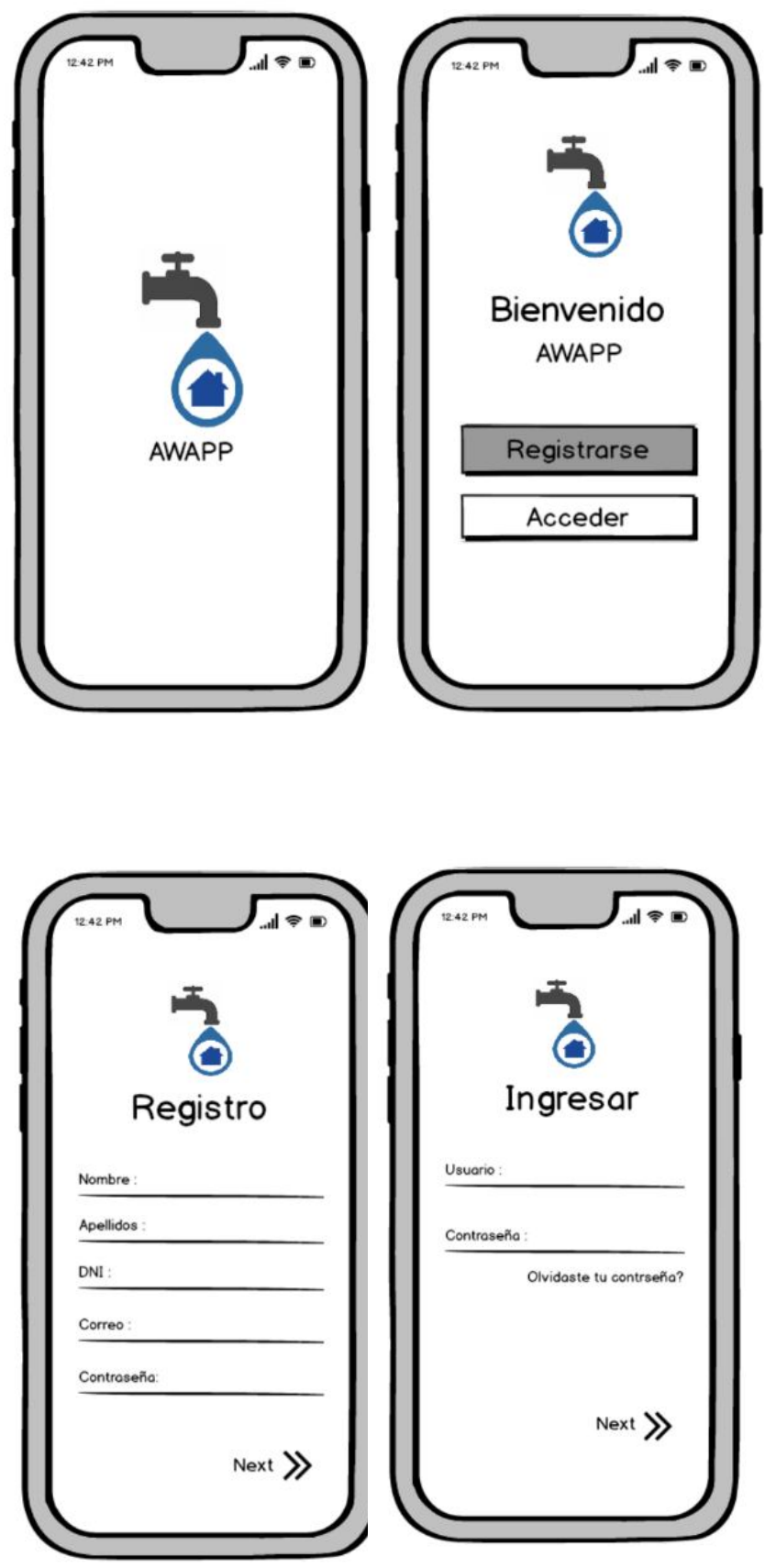

Figure 4: (a) User registration, (b) User access
If you choose the option to register you will be sent to a form, as you can see in Fig.5, which will ask us for our personal data, to be able to access the use of our application, then when we enter the Access section we will place the user and password, with which we register when we start the application.

When we enter our application, a list of questions will be presented as shown in Fig.6, in which we will know in detail the number of people who live with you, as well as the different uses they give to the water in each home so that we can analyze in a concrete way the amount of water to be used in each use.

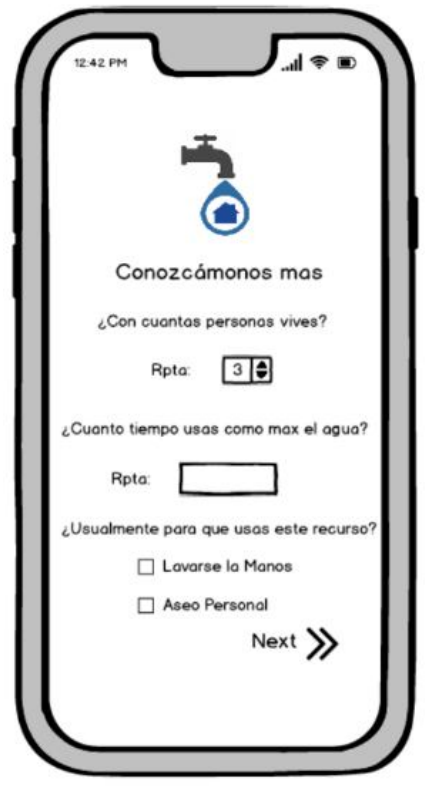

Figure 6: App AWAPP Questionnaire

When the questionnaire is completed, the main screen of the application will be displayed as shown in Fig.7, in which the total amount of water that can be used per day in each household will be seen, depending on the number of people living in the same place, which will be divided into the different actions in which this resource will be used. This way you can also add new actions that could be done in the home by clicking on the more button. 


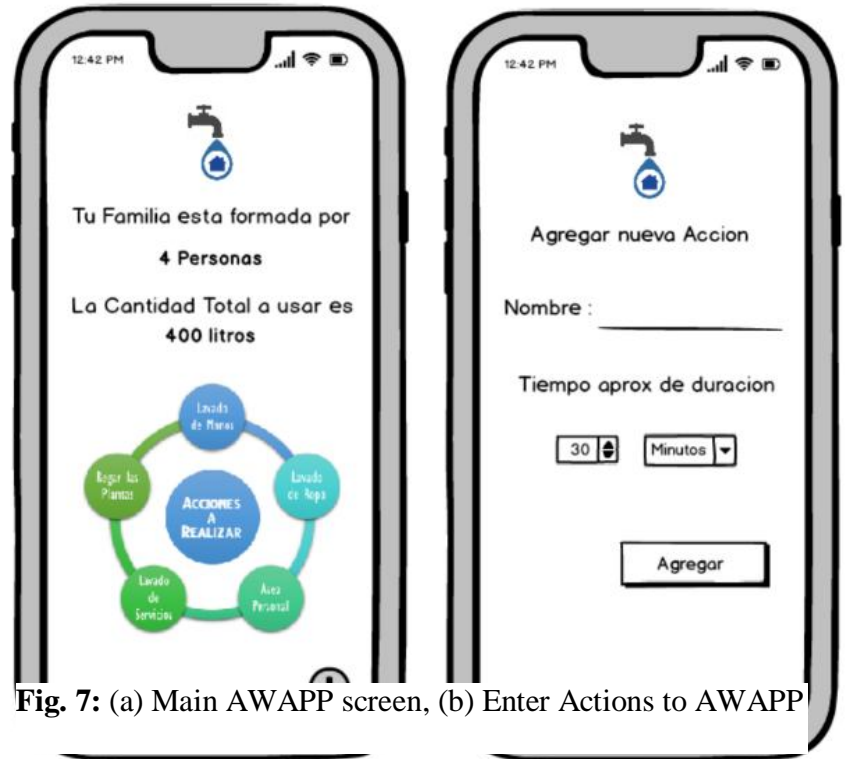

In this last section we will show simple tips as shown in Fig.8, which can be applied from home to achieve in this way to gradually decrease the percentage we have of our water shortage.

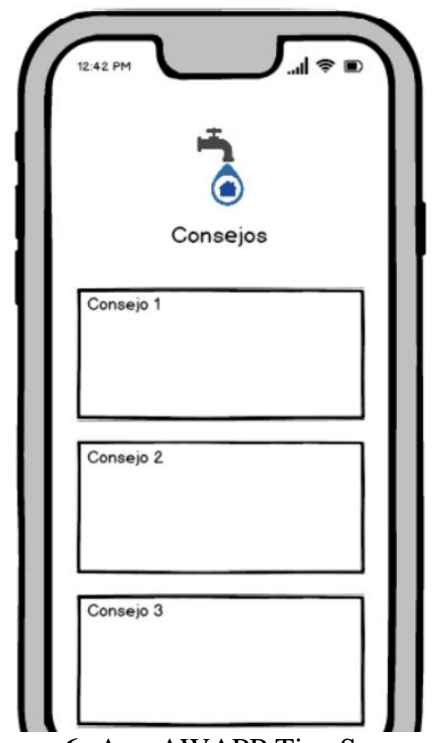

Figure 6: App AWAPP Tips Screen

\section{- Home Water Control System:}

Our water control system would be composed of various components that were explained in detail before, so below we explain the process for proper operation as presented in Fig.3 system to be implemented.

1. First, the infrared sensor can be used to detect whether the key position is accessible for correct use.

2. Then this information will be processed through the Arduino, which will be programmed so that you can validate if the position of the key is correct.

3. And to establish a good sending of the information that is being processed, a connection will be made through the XBEE s2 component, which will process the data.

4. Afterwards, the information is transmitted and sent to the cell phone so that the client can verify that his key is available.

5. When the customer knows that his key is available, through the app "AWAPP", he sends an action that he wants to perform in his home.

6. This information is sent through the XBEE s2 so that the required action is processed and passes correctly to the Arduino.

7. Finally, the Arduino processes the action through its programming and sends the order to the electro valve, which can enable the distribution of water to your home.

\section{Phase IV}

In this IV and last phase when we conclude with our App called "AWAPP", we will start showing it to small groups of people so that they can analyze it and give us constructive criticism so that we can implement these improvements to the development of our application and thus be able to achieve the main objective that we set at the beginning of this research.

\section{RESULTS AND DISCUSSION}

In this section the expected results will be presented with respect to the development of this investigation within the case study, as in its methodology, taking into account the application that will be developed, as well as the implementation of the control system, to later carry out the analysis with other investigations, of which it presents similarities or differences with respect to the development of the chosen methodology, taking into account the phases that intervene in it and in its way of presenting the execution of the development of its application.

\section{A. About the Case Study:}

As a case study, the description that will be developed are of two important points, such as the tools to be used within the application, such as the control system and the design of the mobile application, as well as the design of the control system, which will be carried out. adequately, dividing into different stages so that the functionalities for its proper and correct creation and installation can be developed and implemented, the application that will be prototyped with the help of the Balsamiq Mockups tool as can be seen in Fig. 7, which present the development of what would come to visualize the amount of water to use as well as the different actions that can be involved so that the user can consciously distribute the 
water in his home and its correct use can be easily This resource is being given as important as well as the help provided for its existence in the coming years.

In comparison, certain differences were observed in the development of the mobile application on Android, called HeartBeat [26], which has a very different case study structure than the one presented in this research, since this section is It is distributed by different techniques for a good data collection, for this reason it has the use case diagram, as well as the architecture that its implemented system has and finally the different parts that make up the development of its application are presented, such as the of their website, since the presentation of the App would be entirely for patients and the website so that doctors can continuously monitor their registered patients. There is also the development of another mobile application on Android, called iTourism [27], which will present some similarities with our research, since its case study is structured by the different phases presented by the RAD methodology, finding the difference This section also presents the results obtained when implementing and showing your developed app to a certain amount of the population, which by obtaining the different suggestions that users made, it is possible to see the improvements made in their mobile app by presenting the different tabs that form part of the update of your app with its respective description and the tools that will be used for its correct implementation. Another Android application that will be analyzed is the one that allows a real-time weather monitor [28], which will present the design of the system that they will implement, as well as the data management that they would use, in their case study, explaining each tool carefully. its corresponding use and the different interfaces that the application will present, and finally there will be MEEapp [29], which is an Android application, where it is shown that your case study will also present different sections, since they implement e-learning for the development of your application, showing its general structure, the design of the modules, its characteristics and the results of the different modules, which are explained in detail for its correct implementation.

\section{B. About the Methodology:}

As a methodology, its description is generally of the parts that make up the RAD methodology, due to its agile application development model, therefore the phases to consider in your research are requirements planning, design, construction and last the implementation. Considering thus in the first phase, that their search for reliable results are those that expose the origins that manage to cause the misuse of water, in the second phase they presented the design, as the structure in which they define the programming language to use as their tools that will help the correct implementation of the investigation, having, as well as a third phase, the basic development of the application as the control system, where it will take most of the coding and integration of the different modifications that will be carried out and, lastly, phase, the first sample of the application will be presented to a small group of people so that they can provide suggestions that will later be implemented. Thus, they will have the comparison of other investigations carried out with the same methodology, such as Implementation of Rapid Application Development (RAD). Methodology in the practical development "Training Request System" [30], where the description of a different methodology will be presented. The one that was presented in the research, since it was only detailed how this methodology was implemented within the project in broad strokes, but they did not make the description for each phase to be implemented, they came to consider as advantages that this methodology presented a great facility for its implementation, rapid improvements can be made to the satisfaction of users and only a shorter time to market will be needed. As, another investigation is the Development of an information platform for observation of seismic events in Chile using RAD methodology [31], where they used the methodology that considered three main criteria which are necessary to have a deadline to create a final system. reason why they programmed it in three months, they also considered that the client needs to constantly observe the progress of the system that will be implemented so that the results can be validated and finally they considered the amount of human resources, which will be in charge of development of the project, because they analyzed and derived that for this project to be implemented they have a small group of people, so that later they take into account the four phases of the RAD, they were already explained above, where they consider the speed of development to be an advantage, also will have greater flexibility than other models that help implement platforms Arms and development cycles will be presented with the very short methodology. And finally they obtained another research called Reviews on agile methods in mobile applications - Development process [32], where they analyze different agile methodologies which help for the development of mobile applications taking MobileD, as one of the methodologies that will be referred to in The investigations, since it is made up of five iteration phases, such as the exploration, analysis, ionization of the product, stabilization and repair of the system, but each of these phases has three different types of development, which is why they consider a best implementation for mobile apps lasting eight to ten weeks.

\section{CONCLUSIONS}

In the case study we started with the phases for the detailed explanation about the application called "AWAPP" as a first phase we obtained the origins of the water shortage which were the water contamination by mining tailings and the over exploitation of this resource. Then it was decided in its second phase to start with the structuring of the mobile application and at the same time with the control system for the management of water disposal in the homes that would use the app, in its third phase began to design the prototyping of the mobile application using the tools Balsamiq Mockups 3 and Android Studio. 
For the methodology was used the rapid application development (RAD), which consists of small groups of developers who generally achieve an agility in development processes for the construction of a prototype as this methodology consists of 4 important phases for the development of mobile application and has an orderly and understandable execution.

With the development of this design, it is intended, in the future, to have the implementation of the software in the SMEs of Peru and thus achieve the control of Human Resources, which, currently, is not highly valued in small or medium enterprises due to the lack of technology and incomes.

We wish to carry out an analysis research of the results obtained from our control and application system called "AWAPP" to show the quality and cost function, as expected from a future plan. In addition, as another future objective we would have an alarm that would indicate when we should leave the shower and also be functional with other household tasks. Possibly, the most important element of this application is the gamification by which, if one finishes before the established term of the shower will be accumulating points in a ranking of savings.

\section{REFERENCES}

1. Programa Mundial de Evaluación de los Recursos Hídricos(2017).UNESCO [Online] Available in:http://www.unesco.org/new/es/natural-sciences/enviro nment/water/wwap/facts-and-figures/all-facts-wwdr3/fact -15-water-pollution/

2. Estadísticas Ambientales(Julio 2019).INEI [Online] Available

in:https://www.inei.gob.pe/media/MenuRecursivo/boletin es/ambientalesagos.pdf

3. "Sunass inicia campaña "Yo cuido el agua" para prevenir el derroche del recurso hídrico", Sunass.gob.pe, 2020. [Online].Available:https://www.sunass.gob.pe/websunass /index.php/noticias/item/1714-sunass-inicia-campana-yocuido-el-agua-para-prevenir-el-derroche-del-recurso-hidri co.

4. M. Graf, "La escasez de Agua en el mundo y la importancia del Acuífero Guaraní para Sudamérica: Relación abundancia- escasez", Centro Argentino de Estudios Internacionales, 2006.

5. Recomendaciones para el cuidado del agua - Cuidado del Agua - sedapal.com.pe", Sedapal.com.pe, 2020. [Online]. Available:

http://www.sedapal.com.pe/consejos-de-ahorro

6. SPDA, "Debemos consumir 100 litros de agua al día por persona, pero consumimos hasta 250 litros", SPDA Actualidad Ambiental, 2017. [Online]. Available: https://www.actualidadambiental.pe/debemos-consumir-1 00-litros-de-agua-al-dia-por-persona-pero-consumimos-h asta-250-litros/.

7. Mathur and S. M. Satapathy, "An Analytical Comparison of Mobile Application Development using Agile Methodologies," 2019 3rd International Conference on Trends in Electronics and Informatics (ICOEI), Tirunelveli, India, 2019, pp. 1147-1152, doi: 10.1109/ICOEI.2019.8862532.

8. K. Schwaber y M. Beedle, Desarrollo de software ágil con Scrum. Prentice Hall Upper Saddle River, 2002, vol. 1.

9. B. Boehm, "A survey of agile development methodologies", Laurie Williams, vol. 45, pág. 119, 2007.

10. J. A. Highsmith y J. Highsmith, Ecosistemas de desarrollo de software ágil. Addison-Wesley Professional, 2002, vol. 13

11. N. M. N. Daud, N. A. A. A. Bakar and H. M. Rusli, "Implementing rapid application development (RAD) methodology in developing practical training application system," 2010 International Symposium on Information Technology, Kuala Lumpur, 2010, pp. 1664-1667, doi: 10.1109/ITSIM.2010.5561634.

12. J, Martin, "Rapid Application Development," Macmillan, New York, 1991.

13. INEI, Formas de Acceso al Agua y Saneamiento Básico. Lima: INEI, 2019 [Online] Available in: https://www.inei.gob.pe/media/MenuRecursivo/boletines/ boletin_agua_nov2019.pdf

14. S, Amarro \& J, Valverde, "Metodologías Ágiles", Universidad Nacional de Trujillo, 2007

15. Delgado and J. Sosa, "Mobile application design of geolocation to collect solid waste: A case study in Lima, Peru," 2019 IEEE XXVI International Conference on Electronics, Electrical Engineering and Computing (INTERCON), Lima, Peru, 2019, pp. 1-4, doi: 10.1109/INTERCON.2019.8853594.

16. L. Allison and M. M. Fuad, "Inter-App Communication between Android Apps Developed in App-Inventor and Android Studio," 2016 IEEE/ACM International Conference on Mobile Software Engineering and Systems (MOBILESoft), Austin, TX, 2016, pp. 17-18, doi: 10.1109/MobileSoft.2016.018.

17. V. K. Myalapalli and S. Geloth, "High performance JAVA programming," 2015 International Conference on Pervasive Computing (ICPC), Pune, 2015, pp. 1-6, doi: 10.1109/PERVASIVE.2015.7087004.

18. Tofan, "Drawing Chemical Equipment with Adobe Illustrator, Part 3: Gradients, Retouching, and More Objects," in Computing in Science \& Engineering, vol. 11, no. 2, pp. 60-61, March-April 2009, doi: 10.1109/MCSE.2009.29. 
19. G. B. Bozkurt and S. Tari, "Photoshop plug-ins supporting visual design," 2018 26th Signal Processing and Communications Applications Conference (SIU), Izmir, 2018, pp. 1-4, doi: 10.1109/SIU.2018.8404270.

20. S. Sahri, "Design of a Scalable Distributed Database System: SD-SQL Server," 2006 2nd International Conference on Information \& Communication Technologies, Damascus, 2006, pp. 2918-2919, doi: 10.1109/ICTTA.2006.1684877.

21. Xbee y Arduino (2013). Interactivo [Online] Available in:https://www.arduineando.com/xbee-y-arduino/

22. Thaijiam, K. Woradit, N. Leela and P. Kaewwibool, "Can cell phone electromagnetic radiation harm human health?", 2016 9th Biomedical Engineering International Conference (BMEiCON), 2016.

23. J. M. Aranda, A. J. de Castro, J. Melendez, F. Cortes, I. Fernaindez-Gomez and F. Lopez, "The Design of an Infrared Sensor for the Measurement of Martian Surface Temperature and Gas Concentration," 2009 Spanish Conference on Electron Devices, Santiago de Compostela, 2009, pp. 301-304, doi: 10.1109/SCED.2009.4800491.

24. C. Xu, Y. Zhou, S. Cai, R. Qin, Y. Liang and B. Pang, "Designing and Research of a Solenoid Valve Operating Life Test System", 2012 Second International Conference on Instrumentation, Measurement, Computer, Communication and Control, 2012.

25. X. Villamil, T. Guarda and G. Quina, "Agile software development for mobile applications and wireless interaction with hardware development board (Arduino)", 2018 13th Iberian Conference on Information Systems and Technologies (CISTI), 2018.

26. B. D. D. Cruz et al., "HeartBeat+: A Development of Mobile Application on Recording and Monitoring Blood Pressure Readings for Hypertensive Patients," 2018 IEEE 10th International Conference on Humanoid, Nanotechnology, Information Technology, Communication and Control, Environment and Management (HNICEM), Baguio City, Philippines, 2018, pp. 1-5, doi: 10.1109/HNICEM.2018.8666317.

27. Ismail, S. A. S. A. Kadir, A. Aziz, M. Mokshin and A. M. Lokman, "iTourism Travel Buddy Mobile Application," 2016 10th International Conference on Next Generation Mobile Applications, Security and Technologies (NGMAST), Cardiff, 2016, pp. 82-87, doi: 10.1109/NGMAST.2016.22.

28. Munandar, H. Fakhrurroja, M. I. Rizqyawan, R. P. Pratama, J. W. Wibowo and I. A. F. Anto, "Design of real-time weather monitoring system based on mobile application using automatic weather station," 2017 2nd International Conference on Automation, Cognitive Science, Optics, Micro Electro--Mechanical System, and
Information Technology (ICACOMIT), Jakarta, 2017, pp. 44-47, doi: 10.1109/ICACOMIT.2017.8253384.

29. W. H. S.K., W. B. N.R, P. Johri, S. P. Singh and S. S. G., "EEapp: An Effectual Application for Mobile based Student Centered Learning System," 2018 4th International Conference on Computing Communication and Automation (ICCCA), Greater Noida, India, 2018, pp. 1-4, doi: 10.1109/CCAA.2018.8777733.

30. N. M. N. Daud, N. A. A. A. Bakar and H. M. Rusli, "Implementing rapid application development (RAD) methodology in developing practical training application system," 2010 International Symposium on Information Technology, Kuala Lumpur, 2010, pp. 1664-1667, doi: 10.1109/ITSIM.2010.5561634.

31. M. V. Tombolini Echeverria, S. G. Cornejo and F. A. Pontigo, "Development of an information platform for observation of seismic events in Chile using RAD methodology," 2016 IEEE International Conference on Automatica (ICA-ACCA), Curico, 2016, pp. 1-8, doi: 10.1109/ICA-ACCA.2016.7778515.

32. M. Mahmud and N. A. S. Abdullah, "Reviews on agile methods in mobile application development process," 2015 9th Malaysian Software Engineering Conference (MySEC), Kuala Lumpur, 2015, pp. 161-165, doi: 10.1109/MySEC.2015.7475214. 